\title{
Factors Associated With Glycemic Control among Type 2 Diabetes Patients Attending Mathari National Teaching Hospital, Nairobi Kenya
}

\author{
Ngoyo James Nduati ${ }^{1 *}$, Karanja Simon ${ }^{1}$, Njenga Eva $^{2}$, Muthami Lawrence $^{3}$, \\ ${ }^{1}$ College of Health Sciences, Jomo Kenyatta University of Agriculture and Technology \\ ${ }^{2}$ Diabetes and Endocrinology Centre \\ ${ }^{3}$ Kenya Medical Research Institute (KEMRI)
}

Received: November 22, 2016; Accepted: November 26, 2016; Published: December 02,2016

*Corresponding author: Ngoyo James Nduati, MSc Public Health Student/Diabetes Care Specialist, Jomo Kenyatta University of Agriculture and Technology, P.OBox 62000-00200, Nairobi Kenya. TEL: +254-721258854;E-Mail: jamngoyo@yahoo.com

\begin{abstract}
Introduction: Type 2 Diabetes mellitus is chronic metabolic disorder characterized by hyperglycemia resulting from insulin secretion, insulin action, or both and accounts for over $95 \%$ cases globally. Uncontrolled diabetes may result to complications (retinopathy, nephropathy, neuropathy leading to amputations, stroke, heart attack and sexual dysfunction), glycated hemoglobin below $7.0 \%$ is recommended for good prognosis.The study determined factors associated with glycemic control, among T2DM patient attending Mathari National and Referral Hospital Nairobi, Kenya.

Method: A descriptive cross sectional study design was used systematic random sampling technique to select 149 study subjects T2DM patients. Quantitative data was collected using a structured questionnaire for socioeconomic and patients practice. Key informants interviews and Focus group discussions collected qualitative data.

Blood samples were drawn for Hba1c, lipid profiles, blood sugar and urine for microalbumin Creatinine Ratio analysis. Data was analyzed using Statistical Package for Social Scientists version 20(SPSS). Descriptive analysis was used to summarize the data. Associations between variables were tested using Chi Square statistics. Qualitative data was analyzed thematically after translation and transcription. Difference between parameter estimates were deemed statistically significant at $\mathrm{p}<0.05$

Results: The mean age of study participants was 54 years and a total of $122(81.6 \%)$ out of 149 participants had poor glycemic control with a mean HBA1C of 9.1, 90.6\% having elevated FBS, 37.6\% with elevated T-Chol and $60.4 \%$ having high LDL levels. Twenty four percent had moderately increased UACR while $11.4 \%$ had severely increased UACR. Gender (OR3.029, 95\%CI: 1.287-7.129, $p=0.010)$, FBS (OR=8.14, 95\%CI: 2.541-26.0810, $\mathrm{p}=0.001$ ) and using drugs for other co-morbidities $\mathrm{OR}=2.519,95 \% \mathrm{CI} ; 1.009-6.288, \mathrm{p}=0.035$ ) were associated with glycemic control.

Conclusion: There is a high burden of poor glycemic control among T2DM patients in Mathari National Teaching and Referral Hospital especially women. With the burden of diabetes increasing, emphasis on diabetes awareness and education to fill in the practice gap in glycemic control. Managing FBS and detecting other co-morbidities like, hypertension, kidney problems and dyslipidemia to be done routinely to prevent development of complications.
\end{abstract}

Keywords: Glycemic Control; Type Two Diabetes; Hba1c;

\section{Abbreviations}

FBS: Fasting Blood Sugar; T-Chol: Total Cholesterol; HDL: High Density Lipoproteins; LDL: Low Density Lipoproteins; TGS: Triglycerides; SBP: Systolic blood Pressure; DPB: Diastolic blood pressure; BMI: Body Mass Index; UACR: Urine for Albumin Creatinine Ratio; Kes: Kenya Shillings; OR: Odds Ratio; CI: Confidence Interval; \%: Percentage; KNH: Kenyatta National Hospital; UON: University of Nairobi; ERC: Ethical Review Committee; FGD: Focus Group Discussion

\section{Units of Measurements}

$\mathrm{Mmol} / \mathrm{L}, \mathrm{Kgs} / \mathrm{m} 2, \mathrm{Mg} / \mathrm{mmol}, \mathrm{mm} / \mathrm{Hg}$, \%.

\section{Introduction}

Diabetes Mellitus is a group of metabolic diseases characterized by hyperglycemia resulting from defects in insulin secretion, insulin action, or both. Prolonged hyperglycemia due to diabetes may result to long-term irreversible organ damage like dysfunction, and failure of different organs, especially the eyes, kidneys, nerves, heart, and blood vessels [1].

In the start of 20 th century the disease was not considered a medical priority in Africa unlike today where the world is facing a fast growing number of people living with diabetes with a big number coming from low resource settings regions. Studies done have demonstrated increased incidences in diabetes mellitus [2]. 
Diabetes mellitus has been reported to be a global public health concern of the $21^{\text {st }}$ century with the disease scale of challenge affecting all people regardless of age or social class. [3].

World Health Organization and International Diabetes Federation estimated that almost half of the people are unaware of their diabetes status which is a global and a local threat to health and productivity in the $21^{\text {st }}$ century [3].

The global prevalence of DM is $8.3 \%$ which translates to 382 million people and if nothing is done, the number of people with DM is projected to rise up to 552 million cases by the year 2030 [3]. A study in Australia estimated that, for every 5 newly diagnosed cases of diabetes, there are 4 undiagnosed cases [4].

A study done by [5] estimated that DM is on the rise at the recent past with at least every four out of five people with diabetes living in low and middle income countries. Suboptimal glycemic control may lead to early onset of irreversible diabetes complications which include retinopathy leading to blindness; nephropathy leading to renal failure; peripheral neuropathy with risk of foot ulcers, amputations, and autonomic neuropathy causing gastrointestinal, genitourinary, and cardiovascular symptoms and sexual dysfunction[6].

The estimated global expenditure on diabetes is about USD 465 billion out of which $80 \%$ is attributed to developed countries and only $20 \%$ is available for the developing countries [3]. In United States of America alone diabetes costed the health care system \$ 245 in the year 2012 for both (Direct and indirect), this translated to an average medical expenditures among people living with diabetes to be 2.3 higher than people without diabetes [7].

In Kenya the social economic burden of the disease and its related complications remains a nightmare. This includes cost of treatment, availability of and supply of monitoring equipment, medication and hospitalization. As a result patients and relatives incur both direct and indirect cost due to low productivity, loss of income and diversion of family resources to the disease management [8].

The numbers of Disability have adjusted Life Years in Mexico due to diabetes increase from $7.31 \%$ in 1995 to $9.21 \%$ in the year 2005 , this attributed to amputations at $2 \cdot 62 \%$, to $5 \cdot 83 \%$ as a result of retinopathy, and $0.94 \%$ due to diabetic foot and neuropathy. [9]. Despite the world considering victory of diabetes care among people living with diabetes, there is relatively low and unavailable technology, and access to affordable high-quality essential medicines is still lacking which is the key in ensuring good-quality of care this patients need [10].

A recent study by the ministry of health indicated that inadequate training of primary health care workers, lack of access to essential diabetes medication and technology, low level of awareness and failure to proper documentation of diabetes data has resulted to sub-optimal glycemic controls among patients. Though there is no evidence for diabetes budget patients die from early onset of irreversible complications [8].
Though there is no enough documented data, a study done in Kenya and Uganda indicated that the prevalence of T2DM in the general population to be $12 \%$ in urban parts of Kenya, rural Uganda at $0.6 \%$ [11]. It is estimated that in every 30 seconds, a person living with diabetes loses a limb through amputation. Kenya has not been spared in this pandemic the country is facing a rapid epidemiological transition as a result of technological advancements that are changing lifestyle behaviors [12].

Majority of Kenyans living with diabetes are elderly with limited knowledge about diabetes, negative attitudes and poor management practices about the disease [8]. Socio-economic aspect may influence health outcomes through individual health behaviors, access to care, and processes of care. A substantial body of literature demonstrates that in the general population, material and social deprivation are directly related to disease incidence and prevalence and inversely related to health status [13].

Kenya has been rated number 140 out of 190 countries in terms of healthcare system [14]. Cities all across Africa, and indeed the world, are facing many of the same problems. The prevalence of diabetic foot ulcers was $4.6 \%$ in a tertiary clinic. The risk factors of diabetic foot ulcers in the study were poor glycemic control, diastolic hypertension, dyslipidemia, infection and poor self-care, thus specific attention should be paid to the management of these risk factors in patients with or without diabetes foot ulcers in this clinic [15].

Testing urine for albumin-to-Creatinine ratio for T2DM patients reflects whether there is exertion of albumin thus being accepted as an indicator that may predicts co-morbidities of public health outcomes in T2DM which include hypertension and renal failure [16]. Diabetes has been rated to be the leading cause of kidney disease, heart disease, stroke, adult blindness and non-traumatic lower limb amputations [17].Increasing diabetes prevalence has been reported to be associated with increased diabetes complications among them retinopathy, and if patient's glycemic control is not optimal this complication will be inevitable [18].

The trend of type 2 diabetes patients is on the rise and this call for more similar studies to support Mathari National, Teaching and Referral Hospital achieve its standard of care to diabetes patients. The diabetes outpatient clinic has registered 700 T2DM patients with the number increasing since 2008.

\section{Methods \\ Study design and settings}

This was a descriptive cross sectional study conducted between year the 2015 and 2016. The study population were living with T2DM aged 35 years and above. The consenting participant were attending MNRTH, Nairobi County for management of diabetes. Sample size determination was arrived at 149 participants using the [19].Setting $\alpha 0.05$ was used.

\section{Data Collection}

\section{Structured face to face Interviews}

Participants were interviewed using a structured questionnaire and Focus group discussion guide. The researcher 
and two research assistance conducted a face to face interview to the recruited study participants who consented after being explained the process of gathering the information related to factors associated with glycemic control among T2DM. The Questionnaire was translated in Swahili language for easier understanding. Each interview took between 30-45 minutes

\section{Collection of blood and urine samples}

All the participants had been advised and prepared to fast for at least eight hours before the sample were collected. This was to ensure that sample collected will give accurate results especially for fasting Lipid profiles and fasting blood glucose. The researcher prepared the participants about the study and that the samples collected were purposely to test HBA1C, Lipid profile, Fasting blood glucose and urine for micro albuminuria. Blood in the plain tube for lipid profile sample was spun (separation of cells from serum avoid haemolysis that may affect the results) this is done by centrifugation at 4000 revolution per minute gravity for 4 minutes. Phlebotomist prepared the patients as well and collected the samples as required of him. The samples were transported to the lab using cooler boxes within two hours of collection per the laid standards Operating Protocols. All the laboratory analyses was done at Lancet Kenya Pathology Laboratory using Cobas Integra 400/800plus machine. This is an automated machine with a continuous random -access instrument /analyzer intended for in vitro determination of clinical chemistry for serum, whole blood and urine.

\section{Statistical analyses}

Data was entered, cleaned, edited, validated and analysed stored in a Microsoft Excel database then analyzed using Statistical Package for Social Scientists version 20 (SPSS). Descriptive analysis generated frequency tables, descriptive summaries, comparing mean and confidence intervals. Associations between variables were tested using Chi Square statistics. The level of confidence was set at $\mathrm{p}<0.05$. Qualitative data was analyzed thematically after translation and transcription.

\section{Results}

\section{Sociodemographic characteristic of the study partici- pants}

Table 1, below summarizes demographic characteristics of the study participants showed a mean age of 54.86 years ( $\mathrm{SD} \pm 10.14$; median 54 ) with a range of 46 years. The youngest respondent was 35 years while the oldest was 81 years. Most patients were in the age groups of 41 to 55 years $45.6 \%$ (67) and 56 to 70 years $40.1 \%(59)$ with the two age groups accounting for a total of $85.6 \%$ of the total population. There were $30.69 \%$ (46) males and $69.1 \%$ (103) females yielding a male-to-female ratio of 4:9. The majority of the respondents $75.1 \%$ (112) resided within Nairobi County which translated to $97.3 \%$ (145) being urban dwellers. Over half of the study participants $71.1 \%$ (106) were married at the time of the study. Furthermore results indicated that $42.3 \%$ (63) had attained secondary school education and $40.2 \%$ (60) had attained primary school education. Slightly over half the study participants $53.0 \%$ (79) main occupation was selfemployment and $15.4 \%$ (23) formally employed. The levels of income showed a fairly low income with $63.1 \%$ (94) reporting earnings of less than Kes 10,000 per month.

\section{Duration of diabetes since diagnosis of the study participants}

Figure 1; below indicate the distribution of duration since diabetes diagnosis. Above half of the participants $53.2 \%$ had been diagnosed with diabetes for periods longer than five years.

\begin{tabular}{|c|c|c|c|}
\hline \multicolumn{4}{|c|}{$\begin{array}{l}\text { Table 1.Sociodemographic Characteristics of the study } \\
\text { participants }\end{array}$} \\
\hline & Variable & $\mathbf{n}$ & $\%$ \\
\hline \multirow[b]{2}{*}{ Sample size } & Total population & 149 & 100 \\
\hline & $\begin{array}{c}\text { Age [Years; Mean } \\
( \pm S D)]\end{array}$ & $54.86(\mathrm{SD} \pm 10.14)$ & $\begin{array}{c}\text { Median }=54.00 \\
\text { Range } 46 \\
\min 35 \text { Max } 81 \text { ) }\end{array}$ \\
\hline \multirow{4}{*}{ age } & $\begin{array}{l}\text { Between } 25 \text { and } \\
40 \text { years }\end{array}$ & 11 & 7.5 \\
\hline & $\begin{array}{l}\text { Between } 41 \text { and } \\
55 \text { years }\end{array}$ & 67 & 45.6 \\
\hline & $\begin{array}{l}\text { Between } 56 \text { and } \\
70 \text { years }\end{array}$ & 59 & 40.1 \\
\hline & Above 70 years & 10 & 6.8 \\
\hline \multirow{2}{*}{ Sex } & Male & 46 & 30.9 \\
\hline & Female & 103 & 69.1 \\
\hline \multirow{2}{*}{ Region of } & Central & 27 & 18.1 \\
\hline & Eastern & 5 & 3.4 \\
\hline \multirow{2}{*}{ Residence } & Nairobi & 112 & 75.1 \\
\hline & Nyanza & 5 & 3.4 \\
\hline \multirow{2}{*}{ Residence } & Urban & 145 & 97.3 \\
\hline & Rural & 4 & 2.7 \\
\hline \multirow{4}{*}{$\begin{array}{l}\text { Marital } \\
\text { status }\end{array}$} & Single & 15 & 10.1 \\
\hline & Married & 106 & 71.1 \\
\hline & Widowed & 17 & 11.4 \\
\hline & $\begin{array}{l}\text { Divorced/ } \\
\text { Separated }\end{array}$ & 11 & 7.4 \\
\hline \multirow{2}{*}{ Religion } & Muslim & 3 & 2 \\
\hline & Christians & 146 & 98 \\
\hline \multirow{4}{*}{ Education } & Informal & 13 & 8.8 \\
\hline & Primary school & 60 & 40.2 \\
\hline & $\begin{array}{l}\text { Secondary } \\
\text { School }\end{array}$ & 63 & 42.3 \\
\hline & Tertiary & 13 & 8.7 \\
\hline \multirow{4}{*}{ Occupation } & $\begin{array}{c}\text { Formal } \\
\text { employment }\end{array}$ & 23 & 15.4 \\
\hline & Self employed & 79 & 53 \\
\hline & Casual & 12 & 8.1 \\
\hline & Unemployed & 35 & 23.7 \\
\hline \multirow{5}{*}{$\begin{array}{l}\text { Levels of } \\
\text { income }\end{array}$} & Below 5000 & 51 & 34.2 \\
\hline & 5001 to 10000 & 43 & 28.9 \\
\hline & 10001 to 15000 & 13 & 8.7 \\
\hline & 15001 to 20000 & 15 & 10.1 \\
\hline & Above 20000 & 27 & 18.1 \\
\hline
\end{tabular}


The mean duration since diagnosis of diabetes was 8.09years ( $\mathrm{SD} \pm 6.65$; median 6.5 ) with a median duration of 6.5 years. The lowest duration since diagnosis was 1 year with the highest duration since diagnosis being 28 years. From the grouped duration since diagnosis majority $45.8 \%$ (66) were within the group of five years and below.

\section{Knowledge score of the study participants}

Figure 2, shows the knowledge score from the listed responses per category if a respondent managed to correctly identify at least five of them correctly that respondent was deemed to have good knowledge. From these assumption then a respondent would score a maximum of 15 points. A cumulative score was computed for each of the respondent. From the calculated score the mean knowledge score of 7.15 (SD \pm 3.35 ; median 6.0). The minimum score recorded was 1 while the maximum score of 15 was realized. Using the median score as the cut-off point the individual knowledge scores were then categorized as good knowledge of causes, symptoms and complications of diabetes. Those who scored 6 and below were classified as having poor knowledge which comprised 51.0\% (76) while those who had scored above 6 were classified as having good knowledge $49.0 \%$ (73).

\section{Practice scores of the study participants}

Figure 3, below indicate an overall practices adherence score, the respondent answered 'yes' or 'no' to a set of six diabetes management practices questions. Each 'yes' answer was given a score of 1 and a 'no' and/or 'don't know' a score of 0. From these scores a cumulative score was computed for each respondent. A respondent practicing all the seven would yield a maximum score of 6 . From the cumulative score, the mean score for practice was $2.26(\mathrm{SD} \pm 1.20$; median 3.00 ). Only a $0.7 \%$ of the respondent practiced 5 out of the six recommended while $13.4 \%$ practice none of the management practices. The practice score was then used to categorize the respondents as either adhering or nonadhering to diabetes management. Those who scored a score of 5 (above $80 \%$ practice score) were categorized as adhering while those with below that were classified as non-adhering. From the practice score only one $(0.7 \%)$ of the respondents had good practice.

\section{Medications for co-morbidities of the study partici- pants}

Figure 4, below show thedistribution of co morbidities. From the study population $47.7 \%(71)$ of the respondents reported to be on medications for other condition other than diabetes. Majority of those on medications for other co-morbidities, $75 \%$ ( 51) of them were hypertensive.

\section{Glycemic control in regard to ptimal targets of different body parameter soft he study participants.}

Table 2, below shows various the ranges of the various parameters distribution. As indicators of good diabetes management practices various body measures were taken from each consenting participants. All the participants' body weight

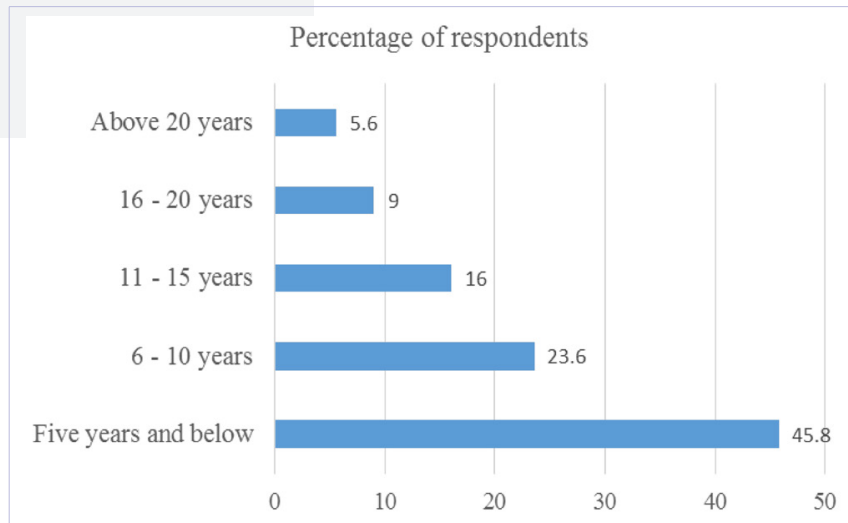

Figure 1: Period since duration of the study participants

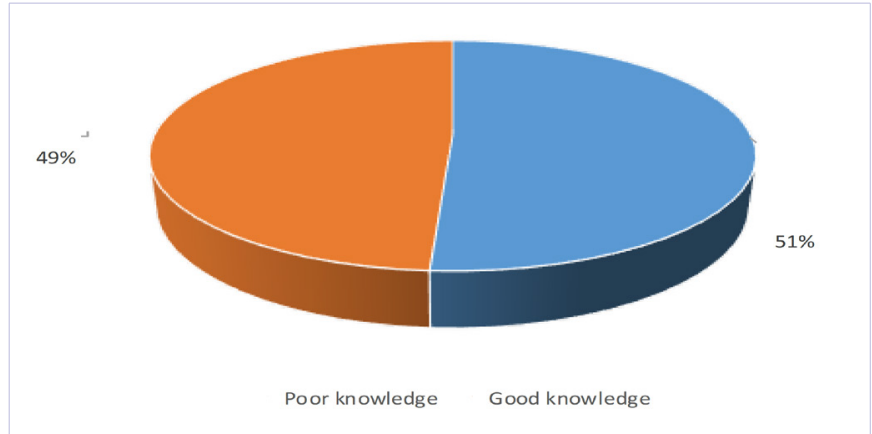

Figure 2: Diabetes knowledge of the study participants

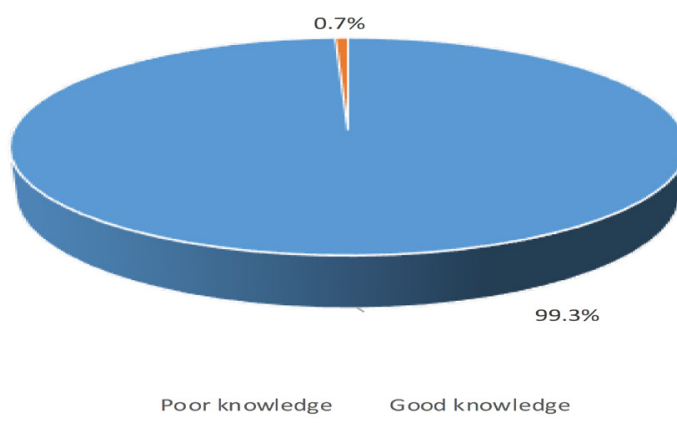

Figure 3: Management practices of the study participants

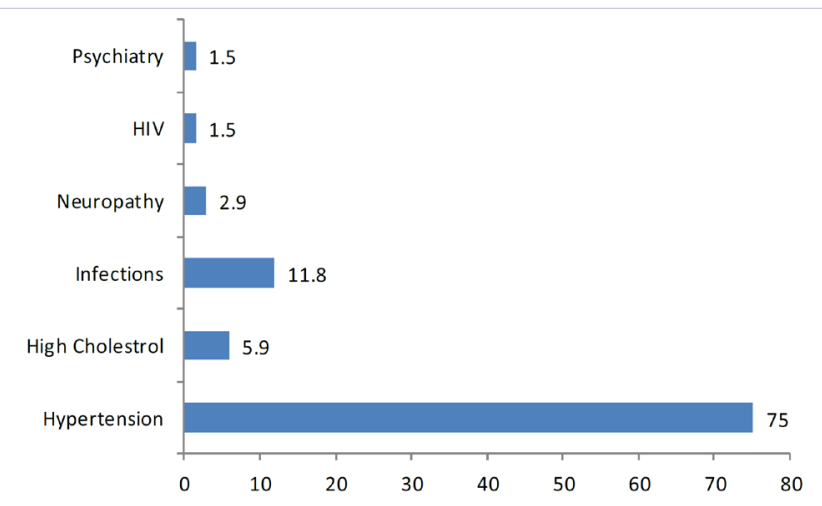

Figure 4: Medications for co-morbidities of the study participant 
and height were taken and later used to compute the bmis of the study population. In general the study population had a mean BMI of $27.9\left(\mathrm{SD} \pm 4.7 \mathrm{~kg} / \mathrm{m}^{2}\right.$; median $\left.27.7 \mathrm{~kg} / \mathrm{m}^{2}\right)$. This indicated that the study population was slightly overweight. When classified into the specific categories only $22.8 \%$ ( 34 ) of the respondents

Table 2: Glycemic control in regard to optimal targets of different body parameters of the study participants.

\begin{tabular}{|c|c|c|c|c|c|c|}
\hline Variables & & $\begin{array}{l}\text { Optimal } \\
\text { levels }\end{array}$ & Min & Max & $\mathbf{n}$ & $\%$ \\
\hline \multirow{3}{*}{$\begin{array}{l}\text { HBA1C } \\
(\%)\end{array}$} & Good glycemic Control & $<7 \%$ & & & 27 & 18.1 \\
\hline & Poor glycemic control & $>7 \%$ & 5 & 14.7 & 122 & 81.9 \\
\hline & $\begin{array}{l}\text { Mean 9.1SD } \pm 2.0, \text { Median- } \\
\text { 8.8,Range-9.7 }\end{array}$ & & & & & \\
\hline \multirow{5}{*}{$\begin{array}{l}\text { BMI } \\
(\mathrm{kg} / \mathrm{m} 2)\end{array}$} & Underweight & $<18.5$ & & & 4 & 2.6 \\
\hline & Normal & $18.5-24.9$ & & & 34 & 22.8 \\
\hline & Overweight & $25.0-29.9$ & & & 70 & 47 \\
\hline & Obese & $>30.0$ & & & 41 & 27.5 \\
\hline & $\begin{array}{l}\text { Mean 27.9SD } \pm 4.7, \text { Median- } \\
\text { 27.9,Range-23.1 }\end{array}$ & & 18 & 41.1 & & \\
\hline \multirow{3}{*}{$\begin{array}{l}\text { FBS } \\
(\mathrm{mmol} / \mathrm{L})\end{array}$} & Normal range & 4-.6.1 & & & 14 & 9.4 \\
\hline & Hyperglycemic & $>6$ & 4.8 & 24.6 & 135 & 90.6 \\
\hline & $\begin{array}{l}\text { Mean } 11.5, S D \pm 4.8, \text { Median- } \\
\text { 10.3,Range-19.8 }\end{array}$ & & & & & \\
\hline \multirow{3}{*}{$\begin{array}{l}\text { SBP } \\
(\mathrm{mm} / \mathrm{Hg})\end{array}$} & Optimal & $<130$ & & & 94 & 63.1 \\
\hline & Off optimal & & 100 & 200 & 55 & 36.9 \\
\hline & $\begin{array}{l}\text { Mean 129SD } \pm 16, \text { Median- } \\
\text { 130,Range-100 }\end{array}$ & & & & & \\
\hline \multirow{3}{*}{$\begin{array}{l}\text { DBP } \\
(\mathrm{mm} / \mathrm{Hg})\end{array}$} & Optimal & $<80$ & & & 103 & 69.1 \\
\hline & Off optimal & & 60 & 100 & 46 & 30.9 \\
\hline & $\begin{array}{l}\text { Mean } \\
80.2 S D \pm 10.4, \text { Median- } 80 \\
\text { Range- } 40\end{array}$ & & & & & \\
\hline \multirow{3}{*}{$\begin{array}{l}\text { T.Cho } \\
\text { (mmol/L) }\end{array}$} & Optimal & $<5.0$ & & & 93 & 62.4 \\
\hline & Off optimal & & 1.9 & 9.5 & 56 & 37.6 \\
\hline & $\begin{array}{l}\text { Mean 5.1SD } \pm 1.2 \text {, Median- } \\
\text { 5.0,Range-7.6 }\end{array}$ & & & & & \\
\hline \multirow{3}{*}{$\begin{array}{l}\text { LDL } \\
(\mathrm{mmol} / \mathrm{L})\end{array}$} & Optimal & $<2.6$ & & & 59 & 39.6 \\
\hline & Off optimal & & 0.6 & 6.1 & 90 & 60.4 \\
\hline & $\begin{array}{l}\text { Mean 3.0SD } \pm 1.0, \text { Median- } \\
\text { 3.0,Range-5.5 }\end{array}$ & & & & & \\
\hline \multirow{3}{*}{$\begin{array}{l}\text { HDL } \\
(\mathrm{mmol} / \mathrm{L})\end{array}$} & Below optimal & $<1.2$ & & & 43 & 28.9 \\
\hline & Optimal levels & $>1.2$ & 0.1 & 2.3 & 106 & 71.1 \\
\hline & $\begin{array}{l}\text { Mean 1.3SD } \pm 0.4, \text { Median- } \\
1.2, \text { Range- } 2.2\end{array}$ & & & & & \\
\hline \multirow{3}{*}{$\begin{array}{l}\text { TGS } \\
(\mathrm{mmol} / \mathrm{L})\end{array}$} & Optimal & $<1.7$ & & & 94 & 63 \\
\hline & Off optimal & & 0.5 & 13.2 & 55 & 36.9 \\
\hline & $\begin{array}{l}\text { Mean-1.8SD } \pm 1.4, \text { Median- } \\
\text { 1.4,Range } 12.7\end{array}$ & & & & & \\
\hline \multirow{5}{*}{ UACR } & $\begin{array}{l}\text { Normal to mildly } \\
\text { increased }\end{array}$ & $<3.0$ & & & 96 & 64.4 \\
\hline & Moderately increased & $3.0-30.0$ & & & 36 & 24.2 \\
\hline & Severely increased & $>30.0$ & & & 16 & 11.4 \\
\hline & No results & & & & 1 & 0.7 \\
\hline & $\begin{array}{l}\text { Mean 19.0SD } \pm 63.9 \text { Median } \\
\text { 1.7 Range 529.4 }\end{array}$ & & 0.2 & 529.5 & & \\
\hline
\end{tabular}

were within the normal ranges of BMI (18.5 to $25 \mathrm{~kg} / \mathrm{m}^{2}$ ) $74.5 \%$ ( 111) of the study population had BMI above $25 \mathrm{~kg} / \mathrm{m}^{2}$ and were classified as either overweight or obese. Fasting blood sugar for all the respondents was also done during the visits. The results showed that a mean of $11.5 \mathrm{SD} \pm 4.8(\mathrm{mmol} / \mathrm{L})$ with a median of 4.8(mmol/L).With regard to FBS $90.6 \%(135)$ had suboptimal target fasting sugars levels above $6.5 \mathrm{mmol} / \mathrm{l}$ while only $9.4 \%($ 14) were classified as being within the normal targets. Blood Pressure measurements were also taken and a mean of 129/80 BP measurements were recorded for the entire population. Upon classifying the individual BP readings $69.1 \%$ ( 103) and $63.1 \%($ 94) of the study participants were within the optimal target for diastolic and systolic BP readings respectively. Blood samples collected from all consenting participants were taken to Lancet laboratories for HBA1C test among other biochemical parameters as indicators of glycemic control. An array of test which included HBA1C, lipid profiles and urine for albumin/creatinine ratios were done. The study participants had a mean HBA1C of $9.1 \%$ ( $\mathrm{SD} \pm 2.0$; median $8.8 \%$ ).Upon categorization of the HBA1C only $27(18.1 \%)$ of the participants had good glycemic control $(<7 \%)$ and $81.9 \%$ ( 122) had uncontrolled glycemic control of above $7 \%$. The mean total cholesterol was $5.1 \mathrm{mmols}(\mathrm{SD} \pm 1.2 \mathrm{mmol} / \mathrm{L}$ with $62.4 \%$ having optimal levels. With regards LDL $60.4 \%$ of the study participants had elevated levels with a mean of 3.0 mmols and 36.9\%having elevated Triglycerides with a mean of $1.8 \mathrm{mmol} / \mathrm{L} / \mathrm{l} \mathrm{SD} \pm 1.8 \mathrm{mmol} / \mathrm{L}$.

\section{Association of HBA1C with demographics and Manage- ment practices of the study participants}

For the purpose of this study glycemic control was define by measures of HBA1C. For those respondents with HBA1C levels above $7 \%$ were classified as having poor glycemic control. As shown in Table 3 below, the study respondents were classified into two groups as either good or poor glycemic control using HBA1C. This was then cross tabulated with various factors deemed to have an influence or effect on the respondents' glycemic control. For all the variables cross tabulated with HBA1C, gender was significantly associated with the glycemic control at with Crude Odds ratio (OR3.029, 95\% CI: 1.287-7.129, $\mathrm{p}=0.010$ ). Respondent's knowledge on causes, symptoms and complications association with HBA1C glycemic control did not show any statistical association $(\mathrm{OR}=1.117,95 \% \mathrm{CI} ; 0.479$ $2.606, p=0.486$ ). Education levels of the participants also showed no any statistically significant association at $\mathrm{p}=0.322$ ). On the other hand neither occupation nor level of income showed any significance with a $\mathrm{p}=0.985$ and $\mathrm{p}=0.723$ respectively. Despite of no significant association between residence and glycemic control, $97.5 \%$ of participants residing in urban centers had poor glycemic control (OR=0.647, 95\% CI; 0.065-6.475, $\mathrm{p}=0.55$ ). Though duration of diabetes was not significance, participants who had lived with diabetes for five years and below had poor glycemic control unlike the once living with diabetes for 16 years and above $(\mathrm{p}=0.587)$. Using drugs for other co-morbidities was significantly associated with glycemic control with $68 \%$ of the participants having good glycemic control while $45.8 \%$ had poor glycemic control (OR=2.519, 95\%CI; 1.009-6.288, $\mathrm{p}=0.035$ ). Regardless that blood glucose monitoring was not significantly 
Factors Associated With Glycemic Control among Type 2 Diabetes Patients Attending Mathari National Teaching Hospital, Nairobi Kenya

Copyright: (C) 2016 Nduati, et al.

Table 3: Association of HBA1C and patients characteristics of the study participants

\begin{tabular}{|c|c|c|c|c|c|c|c|}
\hline \multirow{3}{*}{ Variables } & & \multicolumn{4}{|c|}{ HBA1c } & \multirow{3}{*}{ p value } & \multirow{3}{*}{ OR (CI 95\%) } \\
\hline & & \multicolumn{2}{|c|}{ Good control< 7} & \multicolumn{2}{|c|}{ Poor control> 7} & & \\
\hline & & $\mathbf{n}$ & $\%$ & $\mathbf{n}$ & $\%$ & & \\
\hline \multirow[t]{3}{*}{ BMI } & Underweight & 0 & 0 & 2 & 1.7 & \multirow{3}{*}{0.752} & \multirow{3}{*}{$\mathrm{N} / \mathrm{A}$} \\
\hline & Normal & 7 & 25.9 & 27 & 22.5 & & \\
\hline & Overweight & 20 & 74.1 & 91 & 75.8 & & \\
\hline \multirow{2}{*}{ Diabetes Knowledge } & Good Knowledge & 16 & 59.3 & 69 & 56.6 & \multirow{2}{*}{0.486} & \multirow{2}{*}{$1.117(0.479-2.606)$} \\
\hline & Poor Knowledge & 11 & 40.7 & 53 & 43.4 & & \\
\hline \multirow{2}{*}{$\begin{array}{l}\text { Management } \\
\text { Practice }\end{array}$} & Poor Practice & 26 & 96.3 & 122 & 100 & \multirow{2}{*}{0.181} & \multirow{2}{*}{0.963 (0.894- 1.037) } \\
\hline & Good practice & 1 & 3.7 & 0 & 0 & & \\
\hline \multirow{4}{*}{ Age group } & Between 25 and 40 years & 0 & 0 & 11 & 9.1 & \multirow{4}{*}{0.229} & \multirow{4}{*}{$\mathrm{N} / \mathrm{A}$} \\
\hline & Between 41 and 55 years & 11 & 42.3 & 56 & 46.3 & & \\
\hline & Between 56 and 70 years & 14 & 53.8 & 45 & 37.2 & & \\
\hline & Above 70 years & 1 & 3.8 & 9 & 7.4 & & \\
\hline \multirow{4}{*}{ Marital status } & Single & 1 & 3.7 & 14 & 11.5 & \multirow{4}{*}{0.515} & \multirow{4}{*}{$\mathrm{N} / \mathrm{A}$} \\
\hline & Married & 22 & 81.5 & 84 & 68.9 & & \\
\hline & Widowed & 2 & 7.4 & 15 & 12.3 & & \\
\hline & Divorce/separated & 2 & 7.4 & 9 & 7.4 & & \\
\hline \multirow{2}{*}{ Gender } & Male & 14 & 51.9 & 32 & 26.2 & \multirow{2}{*}{0.01} & \multirow{2}{*}{$3.029(1.287-7.129)$} \\
\hline & Female & 13 & 48.1 & 90 & 73.8 & & \\
\hline \multirow{3}{*}{$\begin{array}{l}\text { Household } \\
\text { Members }\end{array}$} & Three and below & 10 & 40 & 63 & 52.5 & \multirow{3}{*}{0.523} & \\
\hline & Between 4 and 7 members & 14 & 56 & 53 & 44.2 & & $\mathrm{~N} / \mathrm{A}$ \\
\hline & Above 7 members & 1 & 4 & 4 & 3.3 & & \\
\hline & Informal & 2 & 7.4 & 11 & 9 & & \\
\hline Formloduction & Primary & 13 & 48.1 & 47 & 38.5 & & \\
\hline 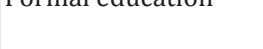 & Secondary & 12 & 44.4 & 51 & 41.8 & 0.024 & $10 \mathrm{~N}$ \\
\hline & Tertiary & 0 & 0 & 13 & 10.7 & & \\
\hline & Formal Employment & 5 & 18.5 & 31 & 25.4 & & \\
\hline Work status & Self employed & 16 & 59.3 & 62 & 50.8 & 0.985 & NA \\
\hline & Unemployed & 6 & 22.2 & 29 & 23.8 & & \\
\hline & below 5000 & 8 & 29.6 & 43 & 35.2 & & \\
\hline & 5001 to 10000 & 9 & 33.3 & 34 & 27.9 & & \\
\hline $\begin{array}{l}\text { Levels of } \\
\text { Income }\end{array}$ & 10001 to 15000 & 4 & 14.8 & 9 & 7.4 & 0.723 & \\
\hline & 15001 to 20000 & 3 & 11.1 & 12 & 9.8 & & \\
\hline & Above 20000 & 3 & 11.1 & 23 & 18.9 & & \\
\hline & Urban & 25 & 96.2 & 116 & 97.5 & & \\
\hline Nesictente & Rural & 1 & 3.8 & 3 & 2.5 & 0.551 & $0.64 /(0.065-6.4 / 5)$ \\
\hline Diagnosis period & below 5 years & 11 & 42.3 & 55 & 46.6 & & \\
\hline
\end{tabular}




\begin{tabular}{|c|c|c|c|c|c|c|c|}
\hline & $6-10$ years & 9 & 34.6 & 25 & 21.2 & \multirow{4}{*}{0.587} & \multirow{4}{*}{$\mathrm{N} / \mathrm{A}$} \\
\hline & $11-15$ years & 4 & 15.4 & 19 & 16.1 & & \\
\hline & $16-20$ years & 1 & 3.8 & 12 & 10.2 & & \\
\hline & Above 20 years & 1 & 3.8 & 7 & 5.9 & & \\
\hline \multirow{2}{*}{ Co-morbidities medications } & Yes & 17 & 68 & 54 & 45.8 & \multirow{2}{*}{0.035} & \multirow{2}{*}{$2.519(1.009-6.288)$} \\
\hline & No & 8 & 32 & 64 & 54.2 & & \\
\hline \multirow{4}{*}{ Monitor Glucose } & Daily & 5 & 33.3 & 18 & 22.5 & \multirow{4}{*}{0.56} & \multirow{4}{*}{ NA } \\
\hline & Weekly & 4 & 26.7 & 14 & 17.5 & & \\
\hline & Monthly & 5 & 33.3 & 40 & 50 & & \\
\hline & Never & 1 & 6.7 & 8 & 10 & & \\
\hline \multirow{2}{*}{ Do exercise } & Yes & 15 & 55.6 & 70 & 61.4 & \multirow{2}{*}{0.364} & \multirow{2}{*}{$1.273(.545-2.971)$} \\
\hline & No & 12 & 44.4 & 44 & 38.6 & & \\
\hline \multirow{2}{*}{$\begin{array}{l}\text { Manage low } \\
\text { Sugar levels }\end{array}$} & Yes & 13 & 100 & 55 & 84.6 & \multirow{2}{*}{0.142} & \multirow{2}{*}{$1.182(1.065-1.311$} \\
\hline & No & 0 & 0 & 10 & 15.4 & & \\
\hline \multirow{2}{*}{ Follow diet } & Yes & 20 & 74.1 & 75 & 64.1 & \multirow{2}{*}{0.226} & \multirow{2}{*}{$0.625(0.244-1.600)$} \\
\hline & No & 7 & 25.9 & 42 & 35.9 & & \\
\hline \multirow{2}{*}{ Have hotline } & Yes & 3 & 11.1 & 14 & 12 & \multirow{2}{*}{0.602} & \multirow{2}{*}{$1.087(0.289-4.086)$} \\
\hline & No & 24 & 88.9 & 103 & 88 & & \\
\hline \multirow{2}{*}{ Keep appointments } & Yes & 20 & 74.1 & 84 & 71.2 & \multirow{2}{*}{0.483} & \multirow{2}{*}{$0.865(0.335-2.232)$} \\
\hline & No & 7 & 25.9 & 34 & 28.8 & & \\
\hline \multirow{3}{*}{ Diabetes expenditure } & 1000 & 11 & 44 & 44 & 37.3 & \multirow{3}{*}{0.333} & \multirow{3}{*}{ NA } \\
\hline & 1001 to 5000 & 11 & 44 & 68 & 57.6 & & \\
\hline & $>5000$ & 2 & 8 & 3 & 2.5 & & \\
\hline
\end{tabular}

associated with glycemic control, $33 / 3 \%$ of the participants monitored their glucose levels daily, $26.7 \%$ testing once a week, $33.3 \%$ test monthly while $6.7 \%$ never test their sugar at home; of those with poor glycemic control 22.5\%tested their glucose daily, $17.5 \%$ weekly, $50 \%$ monthly and $10 \%$ testing during clinic days $(p=0.56)$. Physical activity was not significant with glycemic control with $61.4 \%$ of those who were physically active having poor glycemic control $(\mathrm{OR}=1.273$, 95\% CI; 0.545$2.971, p=0.364$. Study participants $100 \%$ who were found being able to manage low blood sugar had good glycemic control although this was not significantly associated with glycemic control(OR=1.182,95\%CI;1.065-1.311,p=0.142). The results showed that $74.1 \%$ of participants following the prescribed diet had good glycemic control while $64.1 \%$ of the same group had poor glycemic control although this was not significantly associated with glycemic control(OR=0.625,95\%CI;0.244$1.600, \mathrm{P}=0.226)$. The proportion of participants without a hotline line number was not significantly associated with glycemic control as remained the same for those with good and poor glycemic control(OR=1.087,95\%CI;0.289-4.086, $\mathrm{p}=0.602)$. Seventy four percent $74.1 \%$ of participants following clinic appointment date had glycemic control while $71.2 \%$ had poor glycemic control respectively although there was no statistical significance $\quad(\mathrm{OR}=0.864,95 \% \mathrm{CI} ; 0.335-2.232, \mathrm{p}=0.483)$. With regard to monthly medical expenditure the results found out that, (44\%) participants with good glycemic control had a monthly medical expenditure of below Kes 1000 as $57.6 \%$ with monthly expenditure between Kes 1001 - 5000 had poor glycemic control. However there was no statistical significance between monthly medical expenditure and glycemic control ( $\mathrm{p}=0.333$ ).

\section{Association of HBA1C with clinical parameters of the study participants}

Table 4, below indicate that there was no significance of both systolic and diastolic blood pressure and glycemic control (OR=1.211, 95\%CI; 0.502-2.918, $\mathrm{p}=0.423$ ) and (1.711, $95 \% \mathrm{CI} ; 0.639-4.562, \mathrm{p}=0.201)$ respectively although most participants $(66.7 \%$ and $77.8 \%)$ with optimal systolic and diastolic blood pressure had good glycemic control. Serum total cholesterol was not significantly associated with glycemic control (OR=1.508, 95\% CI; 0.611-3.733, p=0.252). Out of the study participants $70.4 \%$ had good glycemic control while $38.8 \%$ had poor glycemic control. The results showed that $63 \%$ of the participants with off optimal target LDL had good glycemic control 


\begin{tabular}{|c|c|c|c|c|c|c|c|}
\hline & & \multicolumn{2}{|c|}{ Good Glycemic control } & \multicolumn{2}{|c|}{ Poor Glycemic control } & \multirow{2}{*}{ P value } & \multirow{2}{*}{ OD (CI 95\%) } \\
\hline & & $\mathbf{n}$ & $<7 \%$ & $\mathbf{n}$ & $>7 \%$ & & \\
\hline \multirow{2}{*}{ SBP } & Optimal & 18 & $66.70 \%$ & 76 & $62.30 \%$ & \multirow{2}{*}{0.423} & \multirow{2}{*}{$1.211(0.502-2.918)$} \\
\hline & Off optimal & 9 & $33.30 \%$ & 46 & $37.70 \%$ & & \\
\hline \multirow{2}{*}{ DBP } & Optimal & 21 & $77.80 \%$ & 82 & $67.20 \%$ & \multirow{2}{*}{0.201} & \multirow{2}{*}{$1.71(.639-4.562)$} \\
\hline & Off optimal & 6 & $22.20 \%$ & 40 & $32.80 \%$ & & \\
\hline \multirow{2}{*}{ T-Chol } & Optimal & 19 & $70.40 \%$ & 74 & $61.20 \%$ & \multirow{2}{*}{0.252} & \multirow{2}{*}{$1.508(0.611-3.733)$} \\
\hline & Off optimal & 8 & $29.60 \%$ & 47 & $38.80 \%$ & & \\
\hline \multirow{2}{*}{ LDL } & Optimal & 10 & $37.00 \%$ & 46 & $38.70 \%$ & \multirow{2}{*}{0.529} & \multirow{2}{*}{$0.934(0.394-2.215)$} \\
\hline & Off optimal & 17 & $63.00 \%$ & 73 & $61.30 \%$ & & \\
\hline \multirow{2}{*}{ FBS } & Normal range & 8 & $29.60 \%$ & 6 & $4.90 \%$ & \multirow{2}{*}{0.001} & \multirow{2}{*}{$8.14(2.541-26.0810$} \\
\hline & Hyperglycemia & 19 & $70.40 \%$ & 116 & $95.10 \%$ & & \\
\hline \multirow{2}{*}{ HDL } & Below optimal & 9 & $33.30 \%$ & 33 & $27.30 \%$ & \multirow{2}{*}{0.34} & \multirow{2}{*}{$1.333(0.545-3.262)$} \\
\hline & Optimal levels & 18 & $66.70 \%$ & 88 & $72.70 \%$ & & \\
\hline \multirow{2}{*}{ TGS } & Optimal & 18 & $66.70 \%$ & 74 & $61.70 \%$ & \multirow{2}{*}{0.4} & \multirow{2}{*}{$1.243(0.515-2.999)$} \\
\hline & Off optimal & 9 & $33.30 \%$ & 46 & $38.30 \%$ & & \\
\hline \multirow{3}{*}{ UACR } & Normal to mildly increased & 18 & $66.70 \%$ & 78 & $64.50 \%$ & \multirow{3}{*}{0.618} & \\
\hline & Moderately increased & 5 & $18.50 \%$ & 31 & $25.60 \%$ & & \\
\hline & Severely increased & 4 & $14.80 \%$ & 12 & $9.90 \%$ & & \\
\hline
\end{tabular}

while $61.3 \%$ of the same population had poor glycemic control. There was no significance between LDL and glycemic control (OR=0.934, 95\% CI; 0.394-2.215, $\mathrm{p}=0.529)$. There was statistical significance between fasting blood sugar and glycemic control as $95.1 \%$ of participants with elevated fasting sugars had poor glycemic control and $29.6 \%$ with fasting blood sugar within target had good glycemic control (OR=8.14, 95\% CI; 2.541-26.0810, $\mathrm{p}=0.001$ ).Surprisingly $72.7 \%$ of the participants with optimal levels of HDL presented with poor glycemic control with slightly more than a half of the participants $66.7 \%$ having good glycemic control. There was no statistical significance between HDL and glycemic control (OR=1.333, 95\% CI; 0.545-3.262, $\mathrm{p}=0.34$ ). Above $66.7 \%$ of participants with optimal serum triglycerides had good glycemic control with $38.2 \%$ of participants having off optimal triglyceride levels having poor glycemic control. There was no significance between serum triglycerides and glycemic control (OR=1.243, 95\% CI; 0.515-2.999, $\mathrm{p}=0.4$ ). With regard to Urine for micro albumin creatinine ratio, $35.5 \%$ with moderate to severe levels albumin creatinine ratio had poor glycemic control. There was no statistical significance between urine for albumin creatinine ratio with glycemic control $(\mathrm{p}=0.618)$.

\section{Discussion}

With the global burden of Diabetes estimate being 382 million, if no measures is done the figures might rise to 592 by the year 2035[3].This study aimed at determining the factors associated with glycemic control among T2DM patients attending Mathari
National Teaching and Referral Hospital, Nairobi County.

\section{Socio-demographic and economic characteristics}

Majority of the study participants were between the age of 41-55; this is in line with other studies that indicated that people in age group of 50-60 years are the majority affected by T2DM [20].The study further found out that a higher prevalence of poor glycemic control was present in the same age group, those who were married, females gender, those who had attained secondary education, self-employed, and those who lived in urban area, those with three and below number of households members.

It was further detected that a higher prevalence of good glycemic control was exhibited by those of age group of 5670 , married, male, those who had between 4 and 7 household members, primary education, self-employed, those earned 500110000 per month, from urban residence.

\section{Glycemic control}

In this study overall glycemic control was poor with only $18.1 \%$ of the study participants having good glycemic control while $81.9 \%$ had $\mathrm{HBA} 1 \mathrm{C} \geq 7 \%$ with mean HBA1C was $9.1 \%$ $( \pm 2.0)$. This was higher than others conducted in India that reported 78.6\% having $\geq 7 \%$ [21], Saudi Arabia reporting 78\% with $\mathrm{HBA} 1 \mathrm{C} \geq 7 \%$ [22], in Cameroon and Guniea showing 74\% of $\mathrm{HBA} 1 \mathrm{C} \geq 7 \%$ [23]. Interestingly studies carried out in Germany and Japan showed $45 \%$ and $65 \%$ respectively having managed to achieve optimal HBA1C targets for T2DM patients. The current 
findings however was slightly lower compared to ADA Guidelines report [24] that $26.3 \%$ of T2DM had good glycemic control. The difference between the current study findings and that of developed countries (Germany and Japan in this case) could be as a result of knowledge difference of participants between developing and developed countries, lack of uniform guidelines for assessing glycemic control for physicians to set the cut off and health insurance and the difference in health insurance access and coverage at primary care $[25,26]$.

\section{Factors associated with glycemic control}

Gender, co-morbidities and fasting blood sugar (FBS) were found to be important factors associated with glycemic control. Poor glycemic control was significantly higher in females than in males which is in line with a previous study [27] where women with T2DM had significantly higher in hba1c levels. Significantly fewer women achieved target hba1c levels of less than 8\% compared to men. It further was found in this current study that gender was significantly associated with poor glycemic control although it contrasted with other studies that showed no significant association [28]. Other comorbidities (on other medication) was found to be significantly associated with glycemic control which was in line with the study by [29] The study findings found a significant association between FBS and glycemic control that was similar to a study done in Chennai [30].The study further found no significance between BMI and glycemic control although the mean BMI was $27.9 \mathrm{~kg} / \mathrm{m}^{2}$ with most participants being overweight or obese. This concurred with a study done in Malaysia [31] With regards to the current study findings, there was no statistical significance between age and glycemic control similar to [32] study that reported the same. Obesity has been reported as a factor associated with poor glycemic control among T2DM may hinder managing and controlling patients' glycemic levels [33].

The study found no significant association between duration of diabetes, age, LDL, HDL and blood pressure. This was consistent with[34].Hypertension being a cardiovascular risk factor to T2DM patient, three quarters of the study participants were on antihypertensive which enabled them to attain mean BP of $129 / 80 \mathrm{~mm} / \mathrm{Hg}$ as per the targets recommended by Kenya National Clinical Guidelines for Management of Diabetes Mellitus 2010.With regards to T2DM, dyslipidemia is a coronary artery disease and macro vascular disorders risk factor and 2-5 fold than in non-diabetic subjects[35], less than $6 \%$ of the population were on lipids medication although $37.6 \%$ and $60.4 \%$ had optimal total cholesterol and LDL.

This was supported by qualitative themes where FGD group members who unanimously said "The reason was because the doctors are changed weekly and they don't have enough time to explain the results as there are many patients to be cleared. Also we don't know even which tests we need to be tested or examinations needed for our condition" [FGD members].

And also had this to say "Whenever you ask, the answer is all is well now you don't know what next and as far as the doctor give you the laboratory request without explanation how do we know and after that you are prescribed expensive drugs and yet you are told all is well". [FGD members].
This could also be due to the fact that over half of the participants were reported to be skipping their medication. The Key informant also had this to say It's also good for the patients to be assisted by the government and health facilities to look for ways of ensuring that all diabetes patients are provided with right drugs and done all their annual tests at the right time so as to prevent diabetes complications and improving their quality of life" [sister in charge of the clinic, 2016].

On the same note an FDG discussant quote that "So unfortunate that diabetes is a very expensive condition to manage because if you can't manage to buy medications, laboratory charges or even buying most of the prescribed diet like brown foods needed there is a lot of expenses more than a non-diabetic case". (FGD male 68 years).

While"Majority said that controlling diabetes without knowing the glucose levels is hard, drugs are very expensive to buy especially the new drugs in the market as well as issues with taking food that you even don't have knowledge about".(FGD members).

The clinic in-charge also noted that "More so the hospital should be provided with proper Diagnostic/laboratory equipment for ensuring that all patients are tested for their annual checkups as well as having sufficient diabetes and hypertensive drugs in the facility" [sister in charge of the clinic, 2016].

She aggressively said that "The hospital should always emphasis on creating more awareness by carrying outreach services to the community members and liaising with other stakeholders to collaborate in Diabetes Care" [sister in charge of the clinic, 2016].

\section{Conclusions}

Based on the discussion from the current study of T2DM patients attending Mathari National Teaching and Referral Hospital, Nairobi County; following conclusions were arrived at;

Majority of the study participants were middle aged, female, living in urban residence, married, Christians, had attained secondary school education, were self-employed and earned less than Kes 5,000 a month.

Majority (81.9\%), of the study participants had poor glycemic control with a HBA1C mean of $9.1 \%$.Females were more affected than their male counterpart.

Majority (75\%) of the participants on the current study were being treated for hypertension and $6 \%$ on statins (although $37.6 \%, 60.4 \%, 71.1 \%$ and $36.9 \%$ had off optimal levels of TC, LDL, HDL and TGS respectively).

The factors that were of significance in poor glycemic control in the current study were gender, FBS and being on medications for other co-morbidities. Half the participants had good knowledge on diabetes but $99 \%$ had poor practice.

\section{Acknowledgement}

The researcher do wish to acknowledge all the study participants, research assistants and my supervisors for their quality time and valuable contribution. We greatly thank NOVO NORDISK main sponsors and source of Funding to this study in a 
great manner, and Lancet Kenya for quality results. Not forgetting the Mathari Hospital administration for permitting and assigning doctors and a nursing officer at the diabetes clinic who embraced the study and guided us accordingly and who is dedicated in diabetes care. Special regards my Research assistants Achuka George (Blessed Medicare Centre), Dr. Muthoni Gichu (MOH) and Richard Mutisya (KEMRI).Dr.Joseph Mutai (KEMRI) and Dr. Francis Kirimi from Kenyatta University. Brother Peter Ngoyo for the financial and moral support.

\section{Declarations}

\section{Competing Interests}

The author declares no competing interest (N/A). All the study participants were provided with a written informed consent which they signed voluntarily.

\section{Ethical Consideration}

Upon completion of the research proposal, the researcher sought an ethical approval from Kenyatta National Hospital and University of Nairobi (Ref: KNH-UON/A/303) prior the commencement of any field activities. A clearance letter was issued to the researcher by the Hospital administration to undertake the research in Mathari Hospital. The researcher assisted by research assistants also obtained a written informed consent from each participant with privacy and confidentiality observed by assigning the participants different code numbers.

Data collected was stored by the researcher under key and lock at a specific room before being entered in a excel spread sheet.

\section{References}

1. American Diabetes Association. Diagnosis and classification of diabetes mellitus. Diabetes Care. 2010;33(suppl 1):S62-S69.doi. org/10.2337/dc10-S062.

2. Kengne AP, Dzuide AI, Fezeu LL, Mbanya JC. Impact of Secondary Foot Complications on the Impatient Department of the Diabetes Unit of Yaounde Central Hospital. Lower extremity Wounds. 2006; 59(1): 64 68.

3. International Diabetes Federation. IDF Diabetes Atlas, 6th edn. Brussels, Belgium: International Diabetes Federation, 2013.

4. Valentine N. A, Alhawassi T. M, Roberts G. W, Vora P.P, Stranks S.N, Doogue M.P. Detecting undiagnosed diabetes using glycated hemoglobin: an automated screening test in hospitalised patients.Med J Aust. 2011;194(4):160-164.

5. Jean Claude N Mbanya, Ayesha A Motala, Eugene Sobngwi, Felix $\mathrm{K}$ Assah, Sostanie T Enoru. Diabetes in Sub-Saharan Africa. The Lancet.2010;375(9733): 2254-2266. doi.org/10.1016/S01406736(10)60550-8.

6. International Diabetes Federation - Global Diabetes Plan 20112021Intensive blood-glucose control with sulfonylureas or insulin compared with conventional treatment and risk of complications in patients with type 2 diabetes (UKPDS 33). UK.

7. Center for Disease Control and Prevention. National Diabetes Statistics Report: Estimates of Diabetes and Its Burden in the United States,2014. Atlanta, GA: U.S. Department of Health and Human Services; 2014

8. Maina W. Kiberenge, Zachary M. Ndegwa, Eva Wangechi Njenga, and Eva W. Muchemi. Knowledge, attitude and practices related to diabetes among community members in four provinces in Kenya: a cross-sectional study Pan Afr Med J. 2010;7:2.

9. Jorge Escobedo, Gabriela Rodríguez-Abrego, Juan Aranda, Beatriz Zurita, Teresita Ramirez, Joaquin Herrera. Disability-adjusted lifeyears (DALYs) for diabetes in Mexico in 2005: a cross-sectional burden of disease analysis.2013;381(Sup2):46

10. Adrian J Cameron, David W Dunstan, Neville Owen, Paul Z Zimmet, Elizabeth L M Barr, Andrew M Tonkin,et all.2009.Health and mortality consequences of abdominal obesity: evidence from the AusDiab study. Med J Aust, 2009;191(4):202-208.

11. Christensen DL, Friis H, Mwaniki DL, Kilonzo B, TEtens I,Boit MK, et al. Prevalence of glucose intolerance and associated risk factors in rural and urban populations of different ethnic groups in Kenya. Diab Res ClinPract. diabres.2009.03.007. 2009; 84(3):303-310. doi: 10.1016/j.

12. World Health Organization. Survey of the Stepwise approach for the surveillance of risk factors for non-communicable diseases. Brazzaville: WHO, Region Office for Africa. 2007.

13. Lynch, J. W.; Kaplan, G. A.; Shema, S. J. Cumulative impact of sustained economic hardship on physical, cognitive, psychological, and social functioning. Engl J Med. 1997;337(26):1889-1895. DOI:10.1056/ NEJM199712253372606.

14. World Health Organization. The World Health Report 2000. "Writing Committee. "Body-mass index and cause-specific mortality in 900000 adults: collaborative analyses of 57 prospective studies." The Lancet 373. 2009: 1083-1096.

15. Otieno C. F., V. Vaghela, F. W. Mwendwa, J. K. Kayima, and E. N. Ogola, "Cardiovascular risk factors in patients with type 2 diabetes mellitus in Kenya: levels of control attained at the outpatient diabetic Clinic of Kenyatta National Hospital, Nairobi". East African Medical Journal. 2005;82(Suppl-12):s184-s190.

16. BrantsmaAH,BakkerSJ, de Zeeuw D, de Jong PE, GansevoortRT.Urinary albumin excretion as a predictor of the development of hypertension in the general population. J Am Soc Nephrol. 2006;17(2):331-335. DOI:10.1681/ASN.2005111153.

17. American Diabetes Association. Medical Management of Type 2 Diabetes. Alexandria, VA, American Diabetes Association, 2012.

18. Ruta LM, Magliano DJ, Lemesurier R, Taylor HR, Zimmet PZ, Shaw Je. Prevalence of diabetic retinopathy in Type 2 diabetes in developing and developed countries. Diabet Med. 2013;30(4):387-398. doi: 10.1111/dme.12119.

19. Cochran WG. Sampling Techniques, $3^{\text {rd }}$ edition. New York: John Wiley \& Sons. 1997.

20. King H., Aubert R.E., Herman W.H. Global burden of diabetes, 19952025: prevalence, numerical estimates, and projections. Journal of diabetes care. 1998;21(9):1414-1431.

21. Gopinath B, Sri Sai Prasad M, Jayarama NKP. Study of factors associated with poor glycemic control in Type 2 Diabetic patients. GJMEDPH. 2013;2(2):1-5.

22. Harrabi I, Al Harbi F, Al Ghamdi S. Predictors of Glycemic Control among Patients with Type 2 Diabetes in Najran Armed Forces Hospital: A Pilot Study. J Diabetes Mellitus. 2014;4(2):141-147. DOI: 10.4236/ jdm.2014.42021.

23. Camara A, Balde NM, Sobngwi-Tambekou J, Kengne AP, Diallo MM, 
Tchatchoua AP, et al. Poor glycemic control in type 2 diabetes in the South of the Sahara: the issue of limited access to an HbA1c test. Diabetes Res ClinPract. 2015;108(1):187-192. doi: 10.1016/j. diabres.2014.08.025.

24. American Diabetic, A. Guidelines American Diabetic Association Diabetes Care. 2008;31(s1):S12-S554.

25. Ali MK, Bullard KM, Imperatore G, Barker L, Gregg EW. Characteristics associated with poor glycemic control among adults with self-reported diagnosed diabetes-National Health and Nutrition Examination Survey, United States, 2007-2010. MMWR Morb Mortal Wkly Rep. 2012;61(2):32-37.

26. Islam SM, Niessen LW, Seissler J, Ferrari U, Biswas T, Islam A, et al. Diabetes knowledge and glycemic control among patients with type 2 diabetes in Bangladesh. Springer Plus. 2015;4:284. doi: 10.1186/ s40064-015-1103-7.

27. Kautzky-Willer A, Kosi L, Lin J, Mihaljevic R. AIMS: To determine the impact of gender on glycaemic control and hypoglycaemia ... At the study end, women had a significantly higher insulin dose $/ \mathrm{kg}$ than men 2015;17(6):533-540. doi: 10.1111/dom.12449.

28. Brice Reynolds, D., Walker, R. J., Campbell, J. A.,Egede, L. E. Differential Effect of Race, Education, Gender, and Language Discrimination on Glycemic Control in Adults with Type 2 Diabetes. Diabetes Technology \& Therapeutics, 2015;17(4):243-247. DOI:doi.org/10.1089/ dia.2014.0285.
29. Yerra Rajesh war, Tadele Eticha, Abrahaley Mulu, Hailekiros Gebretsadik, Getu Kahsay, Dagim Ali, Factors Associated with Poor Glycemic Control in Type 2 Diabetic Patients Investigated at Ayder Referral Hospital, Mekelle, Ethiopia . 2016;6(3):160-171.

30. Bachu L, Siddiqui IA, Neha. Comparison of HbA1c and FBS among Diabetics and Non-diabetics to evaluate Role of HbA1c as a Screening Tool. Int J Med Res Rev. 2013;1(3):125-130.

31. Ibrahim SS, Amal K.;Ayman S. Glyceated Hemoglobin Control Among Type 2 Diabetes Patients Attending a Teaching Hospital in Malaysia, Saudi J.Med. Pharm Sci. 2015;1(4):93-102.

32. Kabadi, U. Glycosylation of proteins. Lack of influence on aging. Diabetes Care, 1998;11(5):421-432.

33. Khattab M, Khader YS, Al-Khawaldeh A, Ajlouni K. Factors associated with poor glycemic control among patients with type 2 diabetes. J Diabetes Complications. 2010;24(2):84-89. doi: 10.1016/j.jdiacomp.

34. Firouzi, S., Barakatun-Nisak, M. Y., Azmi, K. N. Nutritional status, glycemic control and its associated risk factors among a sample of type 2 diabetic individuals, a pilot study. Journal of Research in Medical Sciences : The Official Journal of Isfahan University of Medical Sciences, 2015;20(1):40-46.

35. Ministry of health(Kenya), Division of Non-communicable diseases. National Clinical Guidelines for Management of Diabetes Mellitus; 1st Edn website. 